\title{
Blog: Uma Ferramenta de Aprendizagem no Ensino Médio Inovador
}

\author{
Maria Francilene Câmra Santiago' ${ }^{1}$, Rommel Wladimir de Lima ${ }^{1}$ \\ ${ }^{1}$ Universidade do Estado do Rio Grande do Norte (UERN) \\ Núcleo de Educação a Distância - NEAD \\ Mídias na Educação \\ mfsantiago@bol.com.br, rommelwladimir@uern.br
}

\begin{abstract}
This paper analyzes the pedagogical use of the Blog in High School Innovator as a tool for collaborative learning in the construction and systematization of knowledge. The specific objectives were: to see how the school works with the Blog, to analyze the conditions of operation and use of the blog by the school community; investigate how the blog is being used as a learning space for students and verify that it is a tool to improve levels of reading and writing skills of students. To achieve these goals we developed a field research, qualitative and descriptive. The data collection instruments were: analysis of publications in Blog Portal AD and two questionnaires compounds subjective questions applied respectively by the teacher and 23 students involved in the project. The data collected revealed that there are flaws in the methodology, specifically with regard to the revision of the texts by the teacher together with the students, but the blog has been an interesting learning tool because it engages students in educational activities based on formative perspective and serves as a point of departure for the development of new teaching strategies.
\end{abstract}

Resumo. Este artigo analisa o uso pedagógico do Blog no Ensino Médio Inovador, como ferramenta de aprendizagem colaborativa na construção $e$ sistematização do conhecimento. Os objetivos específicos foram: constatar como a escola trabalha com o Blog; analisar as condições de funcionamento e utilização do Blog pela comunidade escolar; investigar como o Blog está sendo utilizado como espaço de aprendizagem pelos estudantes e verificar se está sendo uma ferramenta para melhorar os níveis de leitura e de escrita dos estudantes. Para atingir tais objetivos foi desenvolvida uma pesquisa de campo, de natureza qualitativa e caráter descritivo. Os instrumentos de coleta foram: a análise das publicações no Blog Portal do AD e dois questionários compostos de perguntas subjetivas aplicados respectivamente, junto à professora e os 23 alunos envolvidos no projeto. Os dados coletados revelaram que há falhas na metodologia, especificamente no que diz respeito à revisão dos textos por parte da professora juntamente com os alunos, mas o Blog tem sido uma ferramenta de aprendizagem interessante, pois motiva os estudantes na realização de atividades educativas fundamentadas numa 
perspectiva formativa e serve também como ponto de partida para o desenvolvimento das novas estratégias de ensino.

\section{Introdução}

No mundo de hoje novos desafios se apresentam ao cenário educacional, entre estes o uso pedagógico das diversas ferramentas tecnológicas denominadas de novas tecnologias da informação e comunicação - NTIC's, que apontam novas possibilidades para que o processo de ensino e aprendizagem percorram novos caminhos até então desconhecidos por muitos atores escolares. Esses recursos tecnológicos podem possibilitar uma interação maior entre a escola e o mundo, onde os saberes podem ser produzidos e reproduzidos dialogicamente em tempo real, criando novas possibilidades de acessos as informações que são transformadas em conhecimentos (MORAN, 2000)

Porém, para isso, as Políticas Públicas em Educação no Brasil exigem uma mudança concreta nas práticas educativas em diversas dimensões. Os primeiros artefatos tecnológicos desenvolvidos no passado ainda estão sendo priorizados em algumas situações didáticas; enquanto que as novas tecnologias da informação e comunicação que chegam as escolas muitas vezes permanecem despercebidas e engavetadas em algumas instituições educativas. Percebe-se que mesmo diante das diversas transformações pelas quais o mundo passa, a escola parece que ainda não acompanha a mesma evolução, com isso a educação formal muitas vezes acaba sem acompanhar o ritmo das transformações sociais, políticas e educacionais (LIBÂNEO, OLIVEIRA e TOSCHI, 2003).

O uso eficiente das novas tecnologias educacionais tem provocado discussões acerca das modificações que devem ser realizadas nas propostas educativas que venham assegurar novas ações metodológicas com o uso das mídias educacionais em sala de aula. Com base em Moran (2000), pode-se dizer que nesse novo cenário de mudanças destaca-se a importância de novas práticas pedagógicas que incorporem as mídias educacionais como forma de desenvolver nos estudantes do ensino médio novas habilidades e competências na sua formação. No universo das mídias educacionais, inúmeras ferramentas foram criadas para facilitar a comunicação e a interação entre professores e estudantes. Com o acesso a Internet as pessoas lidam com a informação em tempo real, isso tem facilitado novas formas de produzir e sistematizar conhecimentos, dentro e fora de sala de aula.

Nesse contexto da introdução das Novas Tecnologias da Informação e Comunicação na escola, ressalta-se a importância do trabalho com o Blog no Ensino Médio Inovador pois acredita-se que é uma ferramenta de aprendizagem colaborativa que além de apresentar inúmeras possibilidades de aprendizagem, trabalha fundamentalmente com a leitura e a escrita, sendo possível elevar o nível e a competência da leitura e escrita dos estudantes, que em muitas realidades educativas é um dos grandes problemas enfrentados nesse nível de ensino acima referido.

O objetivo geral do trabalho é analisar o uso pedagógico do Blog no Ensino Médio Inovador, como ferramenta de aprendizagem colaborativa na construção e sistematização do conhecimento. Para isso, este artigo está dividido em mais quatro 
seções. A próxima seção aborda a importância da Internet como nova mídia na educação e analisa o uso do Blog na sala de aula. A terceira e quarta seções apresentam a análise realiza e por fim, na quinta seção são apresentadas as conclusões.

\section{Sala de aula e Internet: Utilizando os Recursos do Blog para a aprendizagem do aluno}

Ao considerar a importância da Internet como mídia que pode contribuir para o processo de construção da aprendizagem do aluno na escola, vale ressaltar os sentidos e formas em que esta pode ser vista no contexto de uma proposta com esse caráter escolar da sala de aula. Segundo Moran (2000, p. 63) "A Internet é um novo meio de comunicação que pode nos ajudar a rever, a ampliar e a modificar muitas das formas atuais de ensinar e de aprender".

Em se tratando de formas, há de se compreender que a diversidade de meios, de ambientes, de informações, ícones e linguagens faz dessa rede um espaço em que o professor, junto com seus alunos pode criar várias maneiras de organizar projetos de ensino que permitam trabalhar com o conhecimento, ora na obtenção de informações, ora no uso das linguagens e códigos que são permitidos para a comunicação na rede.

De acordo com Araújo (2009) a Internet é um veículo comunicacional que permite a troca de experiências sociais, culturais e pessoais, além de possibilitar o esclarecimento de dúvidas sobre diversos assuntos. Como ferramenta de ensino é que ela cria diversas possibilidades para o professor trabalhar, dentro de cada área de ensino, não somente conteúdos, mas a formação de habilidades e competências que são vistas como objetivos de ensino mediante os novos paradigmas que ora surgem como caminhos para a educação no século XXI.

Para Moran (2000) a Internet oferece vários atributos que contribuem para que haja melhores resultados numa aula: pode auxiliar o professor a preparar melhor a sua aula, amplia as formas de lecionar, modifica o processo de avaliação e de comunicação, tanto de professor para aluno, quanto do aluno para com os seus colegas. É, portanto, um instrumento que apresenta infinitas formas e possibilidades, mesmo sem a rede, com ela as vias de acesso ao conhecimento se ampliam.

Existem as redes sociais, a leitura de conteúdos em sítios, páginas, os fóruns, os Blogs e demais ferramentas que podem servir ao processo educativo. Isso faz perceber que o uso da Internet é um caminho viável ao ensino e a aprendizagem, sendo que, para isso é preciso que haja objetivos e metas bem definidos para cada conhecimento que o aluno precisa adquirir. Muitas vezes, professor e aluno aprendem juntos.

Oliveira (2010) lembra que existem materiais de boa qualidade na Internet para serem explorados. Para ela, até os sítios de relacionamentos oferecem caminhos para o professor reunir estratégias de ensino, tanto no que diz respeito a uso seguro quanto para uma análise dos usos linguísticos na comunicação virtual, das formas de expressão que geralmente são usadas nas redes sociais, como: Orkut, Facebook e demais.

Porém, um detalhe importante a ser visualizado nesse sentido, é que o professor deve ter preparo e formação para compreender os anseios dos alunos, pois estes nem sempre veem o uso de uma rede social, por exemplo, como fonte de aprendizagem, 
especialmente na escola. A formação do professor é o ponto forte no contexto de um processo educativo onde se usa a Internet como recurso.

Hack e Negri (2008) analisam que, além de ser preciso o professor aprender a utilizar as mídias, em especial a Internet no processo de ensino e aprendizagem, é importante que ele busque se comportar, não como um monólogo, como ocorre na sala de aula comum, mas como um docente que viva o diálogo, a interação que está ali situada e que é usada normalmente nos ambientes virtuais: nas salas de bate-papo virtuais, nos fóruns e nos e-mails.

\subsection{Características do Blog como Ferramenta Virtual}

A palavra Blog é utilizada para definir popularmente uma ferramenta virtual definida originalmente pelo termo em inglês weblog, que de acordo com Lendengue e Silva (2010), ao ser traduzido significa "arquivo na rede".

Os Blogs são ambientes virtuais no quais se pode criar, editar, publicar, na maioria das vezes gratuitamente e com facilidade de utilização: textos, fotos, vídeos e uma diversidade de materiais criados no próprio computador. Porém, a definição desta ferramenta é cada vez menos consensual porque seu uso tem se expandido e suas ferramentas também. Hoje, há uma diversidade de formas, objetivos e contextos de criação (GOMES, 2005).

A dinamicidade é o primeiro elemento de um Blog. De acordo com Moresco e Behar (2006) apud Lendengue e Silva (2010) os Blogs são ferramentas eficientes e possibilitam desenvolver muitas habilidades e competências relacionadas com as atividades do dia-a-dia do ser humano, entre as quais estão a cooperação, colaboração e autonomia. Assim, são canais de expressão e comunicação relevantes, pois além de poderem guardar conteúdos e informações importantes, promovem o contato entre pessoas de interesses comuns. $\mathrm{Na}$ verdade são ferramentas interativas muito fáceis de manusear e que, qualquer pessoa de boa leitura e escrita pode utilizar.

Os Blogs permitem a publicação de ideias em tempo real; geralmente os textos são curtos e podem ser lidos e comentados; a linguagem é informal e pode ser usada para analisar uma infinidade de assuntos; têm entradas de textos cronologicamente organizados de forma inversa; além de tudo permitem a divulgação de textos, imagens, músicas, capacidade de arquivamento de mensagens anteriores, hiperlinks que complementam o assunto ou relaciona, interliga os Blogs a outros Blogs e a sites (FRANCO, 2006).

Pontes e Castro Filho (2001) enfatizam que os comentários do leitor podem ser desenvolvidos em espaços com links abaixo da matéria publicada, onde o leitor pode dialogar com o autor e vice-versa, concordando, discordando ou acrescentando alguma outra discussão ou elemento. Neste espaço também podem ser sugeridos links para o acesso a outros Blogs, portais ou páginas.

De acordo com os autores supracitados, é este tipo de recurso que cria um incentivo a mais à interação entre os usuários/leitores. Isto também diferencia o ato de "blogar" do ato de navegar na rede. No ato de navegar o usuário/internauta se restringe a traçar o percurso da leitura, no ato de blogar se lê e se escreve, bem como há uma ação coletiva de complexificação e transformação da rede hipertextual pela ação de 
blogueiros e leitores, esta ação, segundo Primo e Recuero (2003) leva os leitores a participarem também como autores a partir de comentários colaborativos.

\subsection{O blog como Ferramenta Educativa na Sala de Aula}

Moresco e Behar (2006, p. 3) citam muitas vantagens quanto ao ambiente de aprendizagem dos Blogs no contexto educacional. Para eles, além de ser um espaço educacional privilegiado por permitir a reflexão sobre a leitura e a escrita, se ampliam as possibilidades de um diálogo mais autêntico e profundo com outras formas de saber, outros pontos de vista, favorecendo a interdisciplinaridade e auxiliando na construção de redes sociais e redes de saberes.

Araújo (2009) faz menção da ideia de que, tanto para o debate de temas atuais quanto para a divulgação de projetos escolares, os Blogs se tornam importantes auxiliadores pedagógicos. São oportunidades de leitura, análise e produção literária de diferentes gêneros narrativos, descritivos ou argumentativos como: poemas, crônicas, contos, opiniões, informações, relatórios de visitas, estudos e excursões, bem como publicações de fotos, desenhos e vídeos produzidos pelos alunos.

Portanto, há como abrir espaço para trabalhar com diferentes áreas. Por exemplo, na área de linguagem pode se explorar os conhecimentos sobre a língua, os usos, as formas, os diversos gêneros textuais (BRASIL, 1997). Em outras áreas, é possível trabalhar com temáticas que podem estimular atividades de pesquisa e de leitura e escrita. Como por exemplo, nas áreas das ciências naturais e biológicas, trabalhar com a genética, reprodução, e a partir disso pesquisar, ver vídeos, ler e escrever.

Barbosa e Granado (2004, p. 69) corroboraram com a ideia de que "se há alguma área onde os weblogs podem ser utilizados como ferramenta de comunicação e de troca de experiências com excelentes resultados, essa área é sem dúvida, a da educação".

Silva e Albuquerque (2009), por exemplo, apresentam cinco categorias de Blogs educacionais: Blogs de professores, onde se pode publicar orientações, textos, vídeos, imagens, animações, referências bibliográficas ou links; Blogs de alunos, usados como portfólios reunindo suas produções e que funcionam como instrumentos de avaliação; Blogs de instituições educativas, voltados à divulgação do trabalho desenvolvido e à autopromoção; Blogs de projetos educativos, destinados à produção e socialização de conhecimentos sobre temas específicos; e Blogs de grupos de pesquisa, reúnem pessoas de comunidades científicas diversas para interlocução, articulação de suas pesquisas, divulgação, análise de resultados e avaliação de textos.

Em toda essa gama de categorias, o mais importante é que, quase que naturalmente o processo de ensino e aprendizagem desenvolvido na construção e manutenção de um Blog, sempre leva o professor a atuar como mediador do conhecimento. Porém, em todo caso, no que tange ao uso do Blog na sala de aula, Araújo (2009) alerta que o professor precisa se apropriar da linguagem para poder explorar junto com os alunos todas as possibilidades de aprendizagem que existem quando se atua na atualização desta ferramenta. 


\section{Procedimentos Metodológicos}

Este estudo baseou-se em pesquisa de campo, de natureza qualitativa e quanto aos objetivos caracteriza-se como uma pesquisa descritiva, pois a finalidade é proporcionar uma análise sobre o Blog e as possibilidades de utilizá-lo no contexto educacional.

A pesquisa foi realizada numa Escola Estadual de Ensino Médio na cidade de Apodi/RN sobre o Blog www.portadoad.blogspot.com de uma professora de história que trabalha com o Ensino Médio Inovador e tem como foco divulgar informações e notícias sobre educação, como também melhorar os níveis de leitura e de escrita dos estudantes. A pesquisa foi desenvolvida com um universo de 23 estudantes e 01 professora, com quem foi aplicado um questionário subjetivo.

Os questionários para a professora e os alunos foram compostos de oito e dez perguntas, respectivamente e abordaram pontos específicos sobre o uso das mídias, em especial das NTIC's, destacando-se o Blog. Neste destaque, foram investigados pontos importantes deste como ferramenta no desenvolvimento da aprendizagem dos alunos. As perguntas de ambos os questionários abordaram: o caráter do Blog usado pelos alunos, as postagens, a escrita, a evolução da aprendizagem dos alunos.

\section{Resultados e Análises}

A investigação das postagens do Blog comprovou que nos escritos publicados pelos estudantes não houve uma preocupação com a escrita formal. Em algumas publicações expuseram as informações de acordo com suas habilidades, individualidades, entendimentos e aprendizado, havendo alguns "erros", diferenças, quando comparados ao padrão da língua culta.

No que se refere aos comentários dos estudantes no Blog demonstraram que estes interagem e se interessam em fazer novas publicações. Apesar de alguns equívocos ortográficos, percebe-se que periodicamente as informações são postadas, sinalizando que buscam manter o Blog sempre atualizado. Isso confirma que o ambiente virtual de um Blog e de grande pertinência para o desenvolvimento de habilidades e competências educacionais, pois contribui de forma mais dinâmica e atrativa para um ensino aprendizagem mais independente, critico e criativo.

Grinspun (2001) afirma ser preponderante acreditar que a educação tecnológica deve ser vivenciada em todos os segmentos de ensino, e cada um destes deve guardar as peculiaridades que o currículo desta provoca no desenvolvimento do aluno, o que pressupõe trabalhar todo o contexto crítico que envolve o uso. Assim, escrever e cometer erros, também abre espaço para a reflexão crítica sobre o uso da língua no contexto do blog.

No que consta dos resultados da entrevista com a professora, esta responde que o Blog foi criado para informar sobre o cotidiano escolar, bem como sobre outros assuntos que venham contribuir para a evolução dos estudantes no processo educacional. Assim, o perfil do referido Blog está limitado a publicações educativas.

Entende-se a necessidade de revisão do universo do Blog, pois essa limitação de informações que padronizou as publicações no Blog. Sabe-se que existem outros recursos e ferramentas disponíveis no Blog que podem ser utilizadas de forma variada e 
sequencial para enriquecer o processo de formação dos estudantes envolvidos nesse projeto.

Quanto ao planejamento de atividades referentes ao Blog, são tarefas contínuas na busca de novas informações, considerando: eventos que a escola realiza, concursos e programas oferecidos para os estudantes do Ensino Médio e projetos que estão sendo desenvolvidos pelos professores na escola. A equipe é distribuída semanalmente. Cada grupo fica responsável para fazer a cobertura e fazer as publicações das informações. Assim afirma a professora.

A avaliação dos alunos, segundo a professora ocorre a partir da frequência dos estudantes nos momentos presenciais, os interesses desses em participarem dos grupos de publicações e edições das informações, análise das postagens, criatividade e desempenho no trabalho realizado no Blog.

Percebemos que no momento da avaliação, que deveria ser o adequado, nem sempre existe um momento de análise das informações antes das publicações. Talvez seja esse o motivo de tanto equívocos ortográficos nas publicações. A correção, entes das postagens, com orientações feitas pela professora ajudaria aos estudantes a melhorarem suas habilidades com uso correto da leitura e da escrita.

As postagens publicadas no Blog são selecionadas sempre considerando o calendário de eventos e atividades que a escola realiza em cada bimestre. As informações que tratam sobre educação também são selecionadas para publicação. Uma das análises referentes a isto é que o Blog precisa ser reavaliado quanto ao limite de publicações, pois existem outras informações que poderiam servir de aprendizado tanto para os estudantes envolvidos no projeto, quanto para quem visita e utiliza as informações.

No momento, o blog somente tem a função de divulgar informações, mas a professora ressalta que poderá no futuro usá-lo como forma de postar poemas ou outros textos. Já quanto aos critérios de distribuição de tarefas para escolha e postagem de informações, são realizados encontros presenciais com a turma de 23 estudantes, através de rodízio, as atividades são divididas nas equipes e em cada equipe existe um coordenador que é responsável pela edição e publicação das matérias.

Ao ser questionada sobre o interesse dos alunos pelas aulas utilizabdo o Blog, ela afirmou que é bem maior do que em outras aulassim, pois nas atividades do Blog, eles apresentam interesse bastante significativo, já as atividades rotineiras de sala de aula eles não tem tanto interesse e muitas vezes faltam essas atividades e nem justificam ou querem fazer em outro momento. Tanto a frequência quanto a participação é maior e bastante significativa nas atividades do Blog. Eles fotografam, entrevistam os professores, buscam informações a toda hora para que o blog esteja sempre atualizado.

Nas respostas coletadas pelo questionário aplicado aos alunos foi enfatizado que o Blog é: local onde se expressa ideias, opiniões, notícias, bem como sentimentos, isto é, serve como forma de comunicação e informação, para ser usado pelos professores e alunos para trocar ideias, publicar artigos e textos, definiram também como rede social, uma vez que permite a divulgação do trabalho escolar, sendo assim um meio de comunicação usado para divulgar notícias atualizadas. 
Os alunos também informaram ter familiaridade com Internet, celular, TV e câmera digital. Dizem usar o celular para comunicar-se com família, amigos, namorados e namoradas, jogar, compartilhar recursos multimídias como fotos e vídeo e acessar a Internet. O computador é utilizado para acessar redes sociais como facebook, twitter, orkut e google plus, fazer pesquisas de conteúdos para atividades de sala de aula e para fazer as postagens no Blog de acordo com as orientações da professora.

Mediante o exposto percebe-se que os estudantes usam esses recursos tecnológicos com muita precisão e eficiência. Todas as ferramentas disponíveis nos aparelhos eles sabem manusear e utilizar com facilidade. Com isso, cabe à escola saber fazer uso desses objetos para produzir e sistematizar novos conhecimentos. É notório que o uso da tecnologia no cenário educacional é de relevante contribuição para o desenvolvimento do processo de aprendizagem dos alunos, bem como para o auxílio das atividades dos educadores (MORAN, 2000).

Porém, questionados sobre a ideia do Blog, os resultados foram os seguintes: $15,69 \%$ não sabiam e nem tinham conhecimento de como surgiu a ideia do Blog; $26,31 \%$ disseram ter sido iniciativa da professora que orienta o $\mathrm{Blog}$; $58 \%$ afirma que o Blog surgiu pela necessidade dos estudantes participarem e se interessarem mais nas aulas, para melhorar a forma de ler e escrever.

Também se observa, por meio dos apontamentos dos entrevistados, que os estudantes não conhecem o Blog surgiu através do Ensino Médio Inovador e do macrocampo Comunicação e Uso de Mídias e que o desenvolvimento dessas atividades integradoras que acontecem no contra turno servem para ampliar o tempo deles na escola, buscando garantir a formação integral através de um currículo mais dinâmico e motivador.

Os estudantes apresentaram ainda as dificuldades que dizem respeito à produção textual a interpretação e entendimento dos textos lidos e ainda, a falta de um laboratório de informática com Internet para que eles pudessem realizar algumas pesquisas e publicações, assim como outras atividades coletivas e conciliar as atividades do Blog com as atividades da sala de aula.

Os aspectos positivos abordados pelos estudantes foram: as pesquisas realizadas nos sites em outros Blogs e que serviram de experiência e aprendizado; novas aprendizagens de assuntos e temas que não conheciam, reuniões realizadas entre os estudantes; o desenvolvimento do trabalho coletivo; o compromisso e responsabilidade com o trabalho pois o Blog sempre precisava se atualizado; trouxe mais atenção e compromisso com o trabalho escolar; interação e amizade entre a professora e os estudantes e melhoria na leitura e na escrita.

Os aspectos negativos abordados foram: os temas para as publicações eram resumidos, pois nem sempre a escola tinha atividades interessantes para serem publicadas; falta de ética de alguns colegas do grupo; não houve viagens para ampliar os campo de pesquisa como aconteceu em outros macrocampos e as atividades começaram tarde depois do primeiro semestre.

Mediante o diagnóstico final onde foram colocados os pontos positivos e negativos pelos estudantes durante o trabalho como Blog na escola percebe-se que os 
aspectos positivos se sobrepõem aos negativos, ou seja, no geral o trabalho apresentou resultados positivos na aprendizagem dos estudantes.

Com os dados coletados da professora e dos estudantes através dos questionários pode-se analisar que no geral o Blog apresentou resultados significativos para a aprendizagem dos estudantes, com isso fica fácil perceber que as Novas Tecnologias da Informação e Comunicação apontam novas possibilidades para o processo de ensino e de aprendizagem, porém, para que essas mídias educacionais venham atingir maiores e melhores resultados os professores precisam estar preparados para trabalhar pedagogicamente com seus recursos.

\section{Conclusões}

A pesquisa no contexto escolar sobre o uso do Blog no ensino médio inovador, fez perceber que na grande maioria gestores e professores ainda não estão preparados para utilizar esses recursos de forma global e contínua, contudo, já estão surgindo experiências significativas com o uso das Novas Tecnologias da Informação e Comunicação em sala de aula.

A pesquisa com a professora e os vinte e três estudantes mostrou a importância de um trabalho diferenciado com o uso do Blog, isso comprova que os recursos tecnológicos disponíveis na escola não podem permanecer no anonimato. Há, portanto, um conjunto de artefatos que se juntam para formar um todo à disposição do professor e do estudante, porém muitas vezes nem um nem outro estão suficientemente aptos a utilizar pedagogicamente esses recursos em favor da sistematização do saber.

Incorporar o uso das mídias educacionais no cotidiano escolar é uma alternativa para tornar o ensino mais atrativo e eficiente, pois as informações produzidas e de fácil acesso podem contribuir para ampliar os caminhos dentro e fora da escola, de forma a produzir saberes essenciais na formação dos educandos, numa perspectiva cidadã.

\section{Referências}

Araújo, M. C. M. U. Potencialidades do uso do blog em educação. Natal: Universidade Federal do Rio Grande do Norte - UFRN, 2009. Dissertação de Mestrado disponível $<$ http://bdtd.bczm.ufrn.br/> Acesso em 21 de janeiro de 2013.

Barbosa, E; Granado, A. Weblogs, Diário de Bordo. Porto Editora, 2004.

Brasil. Ministério da Educação e Cultura. Parâmetros Curriculares Nacionais - Língua Portuguesa. Brasília: MEC/SEF, 1997.

Ferreira, S. M. S. P. Introdução as Redes Eletrônicas de Comunicação. Ciência e Informática. Brasília, v.23, nº. 2, maio/ago, 1994.

Franco, M. F.. Blog Educacional: ambiente de interação e escrita colaborativa. Disponível em: <http://homer.nuted.edu.ufrgs.br/edu3375> Publicado em 2006. Acessado em 20 de dezembro de 2012.

Gomes, M. J. Blogs: um recurso e uma estratégia pedagógica. In: VII Simpósio Internacional de Informática Educativa - SIIE05 Leiria, Portugal, 16-18 Novembro de 2005. Disponível em: <mjgomes@iep.uminho.pt>. Acesso em 20 de janeiro de 2013. 
Grinspun, M P. S. Z. (org.). Educação tecnológica: desafios e perspectivas, $2^{a}$ ed. São Paulo: Cortez, 2001.

Hack, J. R. \& Negri F. Capacitação docente para o uso da mídia como ferramenta didática: um espaço de reflexão e ação. Relatório de Pesquisa apresentado à UFSC e UNOESC, julho de 2008.

Kenski, V. M. Em direção a uma ação docente mediada pelas tecnologias digitais. In: Barreto, R. G. (org). Tecnologias educacionais e educação a distância: avaliando políticas e práticas. Rio de Janeiro: Quartet, 2001.

Lendengue, M.; Silva, K. Blog na educação: criando ambientes virtuais de aprendizagem. Universidade Federal da Paraíba - UFP - Encontro Nacional de Estudantes de Biblioteconomia, Documentação, Gestão, e Ciência da Informação, 18 a 24 de julho de 2010.

Libâneo, J. C., Oliveira, J. F.; Toschi, M. S. Educação escolar: políticas, estrutura eorganização. São Paulo: Cortez, 2003. - (Coleção Docência em Formação/ Coordenação Antônio Joaquim Severino, Selma Garrido Pimenta).

Moran, J. M. Novas tecnologias e mediação pedagógica. Campinas, SP: Papirus, 2000.

Oliveira, E. M. N. Analisando e Planejando a Formação de Professores para o Uso das Mídias na Escola: Uma Proposta. Apodi/RN: CCEAD-PUC RIO. Trabalho de Conclusão de Curso de Especialização em Mídias na Educação - Ministério da Educação - MEC, 2010.

Moresco, S. F. S; Behar, P. A. Blogs para a aprendizagem de física e química. In: CINTED - UFRGS, v. 4, n. 1, jul. 2006.

Silva, L.T. Albuquerque, M. Blogs pedagógicos: possibilidades de interação por meio da escrita coletiva de hipertextos cooperativos. Revista Latino Americana de Tecnologia Educativa - RELATEC, 8 (2), 91-108. 